University of Nebraska - Lincoln

DigitalCommons@University of Nebraska - Lincoln

2006

\title{
Survival of Mycobacterium bovis on Feedstuffs Commonly Used as Supplemental Feed for White-tailed Deer (Odocoileus virginianus)
}

\author{
Mitchell V. Palmer \\ United States Department of Agriculture, Agricultural Research Service, National Animal Disease Center, \\ Ames, lowa, Mitchell.Palmer@ars.usda.gov \\ Diana L. Whipple \\ United States Department of Agriculture, Agricultural Research Service, National Animal Disease Center, \\ Ames, lowa
}

Follow this and additional works at: https://digitalcommons.unl.edu/michbovinetb

Part of the Veterinary Medicine Commons

\footnotetext{
Palmer, Mitchell V. and Whipple, Diana L., "Survival of Mycobacterium bovis on Feedstuffs Commonly Used as Supplemental Feed for White-tailed Deer (Odocoileus virginianus)" (2006). Michigan Bovine Tuberculosis Bibliography and Database. 68.

https://digitalcommons.unl.edu/michbovinetb/68
}

This Article is brought to you for free and open access by the Wildlife Disease and Zoonotics at DigitalCommons@University of Nebraska - Lincoln. It has been accepted for inclusion in Michigan Bovine Tuberculosis Bibliography and Database by an authorized administrator of DigitalCommons@University of Nebraska Lincoln. 


\title{
Survival of Mycobacterium bovis on Feedstuffs Commonly Used as Supplemental Feed for White-tailed Deer (Odocoileus virginianus)
}

\author{
Mitchell V. Palmer, ${ }^{1,2}$ and Diana L. Whipple ${ }^{1}{ }^{1}$ United States Department of Agriculture, Agricultural Research \\ Service, National Animal Disease Center, Ames, lowa, USA; ${ }^{2}$ Corresponding author (email: mpalmer@ \\ nadc.ars.usda.gov)
}

ABSTRACT: Mycobacterium bovis, the causative agent of bovine tuberculosis, has become established in free-ranging white-tailed deer Odocoileus virginianus in northeastern Michigan. The practice of supplemental feeding of white-tailed deer during the winter is believed to contribute to transmission of $M$. bovis between deer. The current study was conducted to determine the ability of $M$. bovis to survive on various feedstuffs commonly used as supplemental feed for deer in northeast Michigan (i.e., apples, corn, carrots, sugar beets, potatoes, and hay) and the effect of maintenance at $-20 \mathrm{C}, 8 \mathrm{C}$, and $23 \mathrm{C}$ on survival. Mycobacterium bovis survived on all feedstuffs at all temperatures tested for at least 7 days. At $23 \mathrm{C}, M$. bovis could still be isolated from samples of apples, corn and potatoes at 112 days. This study suggests that contamination of feedstuffs by $M$. bovis-infected deer could act as a source of indirect transmission between deer because $M$. bovis is able to survive in temperatures similar to those recorded during winter months in northeastern Michigan. Current efforts to ban or control supplemental feeding of deer should have a positive effect on decreasing transmission of M. bovis among deer.

Key words: Feedstuffs, Mycobacterium bovis, Odocoileus virginianus, survivability, tuberculosis, white-tailed deer.

In 1994, a free-ranging white-tailed deer (Odocoileus virginianus) in Michigan was diagnosed with tuberculosis due to Mycobacterium bovis, the causative agent of bovine tuberculosis (Schmitt et al., 1997). Subsequent surveys identified a focus of $M$. bovis infection in free-ranging white-tailed deer in northeast Michigan (O’Brien et al., 2001, 2002). This represents the first known reservoir of $M$. bovis in free-ranging wildlife in the United States and a significant obstacle to the eradication of bovine tuberculosis in domestic livestock. Several factors are thought to have contributed to the estab- lishment and persistence of $M$. bovis in this wildlife reservoir. It is postulated that $M$. bovis was transmitted from cattle to deer at some time during the early to mid 1900s when a large number of Michigan cattle were infected with $M$. bovis (Frye, 1995). During this same period, Michigan's deer population was steadily increasing beyond normal habitat carrying capacity to focal concentrations of 19 to 23 deer per $\mathrm{km}^{2}$ (Schmitt et al., 1997). Transmission and maintenance of $M$. bovis among deer is thought to have been facilitated by the common practice in Michigan of long-term winter feeding of large volumes of sugar beets, carrots, corn, apples, pumpkins, and pelleted feed to deer by private citizens to prevent migration and decrease winter mortality in order to keep deer numbers high for hunting purposes (Schmitt et al., 1997). DNA analysis of $M$. bovis isolates from Michigan white-tailed deer showed that the majority of deer were infected with a common strain of $M$. bovis suggesting a single source of infection (Whipple et al., 1997).

Experimentally, transmission between deer and between deer and cattle has been demonstrated through the sharing of feed with no opportunity for direct contact (Palmer et al., 2004b). Research under a variety of conditions has demonstrated that $M$. bovis can persist for prolonged periods in the environment (Williams and Hoy, 1930; Maddock, 1933; Duffield and Young, 1985; Jackson et al., 1995; Tanner and Michel, 1999). Mycobacterium bovis has been shown to persist in cool, dark environments for 4-6 wk (Duffield and Young, 1985; Tanner and Michel, 1999), on growing grass for as long as $7 \mathrm{wk}$, and 
in liquid manure for at least $16 \mathrm{wk}$ (Williams and Hoy, 1930; Maddock, 1933). In contrast to such prolonged survival, other research has shown survival times of 7-28 days inside dens of brushtail possums in New Zealand (Jackson et al., 1995). Little information exists as to the ability of a particular strain, such as that isolated from white-tailed deer in northeast Michigan, to exist on specific substrates that are commonly used as feedstuffs. This study was conducted to determine the ability of $M$. bovis to survive on various feedstuffs commonly used as supplemental feed for deer in northeast Michigan and the effect of storage temperature on survival.

Mycobacterium bovis strain 1315 was used in the present study. Strain 1315 was originally isolated from a white-tailed deer in northeast Michigan and has the same RFLP pattern as the majority of isolates obtained from deer in Michigan. Bacterial suspensions consisted of mid-log-phase $M$. bovis grown in Middlebrook $7 \mathrm{H} 9$ liquid media supplemented with $10 \%$ oleic acidalbumin-dextrose complex (OADC) (Becton Dickinson Co., Sparks, Maryland) plus 0.05\% Tween 80 (Sigma Chemical Co., St. Louis, Missouri) grown for 10 days at $37 \mathrm{C}$. To harvest bacilli from the culture media, cells were pelleted by centrifugation at 750 $\times \mathrm{G}$ and the pellet resuspended in phosphate-buffered saline solution (PBS, $0.01 \mathrm{M}, \mathrm{pH} 7.2$ ) to the appropriate concentration. Bacterial suspensions were used immediately without freezing.

Samples of sugar beets, apples, carrots, and potatoes were diced into cubes of approximately 1-2 $\mathrm{cm}^{3}$. Samples of alfalfa hay were chopped to approximately 3$4 \mathrm{~cm}$ lengths. Shelled corn was divided into $10 \mathrm{~g}$ samples. Ten grams each of sugar beets, apples, carrots, potatoes, and shelled corn were placed into $50 \mathrm{ml}$ centrifuge tubes. Ten grams of alfalfa hay was similarly placed in suitable plastic bags. To each tube or bag a $1 \mathrm{ml}$ volume of a bacterial suspension containing $1.1 \times$ $10^{6}$ colony forming units (CFU) of $M$. bovis was added. Tubes containing samples and bacterial suspension were rotated thoroughly to ensure mixing of the sample and suspension. Six different types of feedstuffs were examined in duplicate at $2 \mathrm{hr}$, and 1, 2, 3, 7, 14, 21, 28, 56, 84, and 112 days after inoculation. Each evaluation was done at three different environmental temperatures, $-20 \mathrm{C}$ (freezing), $8 \mathrm{C}$ (refrigeration), and $23 \mathrm{C}$ (room temperature), totaling 396 samples.

For isolation of $M$. bovis from carrots, apples, potatoes, and sugar beets, samples were homogenized with $50 \mathrm{ml}$ of nutrient broth containing phenol red. Hay and corn samples were processed by mixing in a hand grinder with $40 \mathrm{ml}$ and $60 \mathrm{ml}$, respectively, of phenol red nutrient broth. Tubes containing samples were thoroughly rinsed with nutrient broth as the sample was extracted for homogenization. Samples were homogenized for $30 \mathrm{sec}$ and allowed to settle for $15 \mathrm{~min}$. Twenty milliliters of suspension was removed, placed in a new 50-ml centrifuge tube, and incubated overnight (16-18 hr) at 37 C. After incubation, an equal volume of 1.0 N NaOH was added for decontamination. After $10 \mathrm{~min}$, the sample was neutralized with $10 \mathrm{~N} \mathrm{HCl}$ to $\mathrm{pH} 7$ and centrifuged at $2,000 \times \mathrm{G}$ for $20 \mathrm{~min}$. The supernatant was decanted and the sediment suspended in $2 \mathrm{ml}$ of phosphate buffered saline (PBS) containing amphotericin B $(50 \mu \mathrm{g} / \mathrm{ml})$. For each sample, two plates containing Middlebrook 7H11 media were inoculated with $0.2 \mathrm{ml}$ of suspension. Plates were incubated at $37 \mathrm{C}$ and growth evaluated at 7 days, $4 \mathrm{wk}$, and 8 wk. Two hundred microliters of each sample were also inoculated into vials of commercial liquid media (BACTEC 12B medium, Becton Dickinson) containing selected antimicrobials for isolation of mycobacteria (BACTEC PANTA Plus, Becton Dickinson). Growth on Middlebrook 7 H11 agar plates was semiquantitatively scored using the following system; 0 (no growth), 1 (1-10 CFU), 2 (11-50 CFU), 3 (51-100 CFU), 4 (>100 CFU). 
Mycobacterium bovis survived on all feedstuffs at all storage temperatures tested for at least 7 days (Table 1). At the termination of the study (112 days), $M$. bovis could be recovered from all feedstuffs at $-20 \mathrm{C}$, from samples of apples, corn, hay, and potatoes at $8 \mathrm{C}$, and from samples of apples, corn and potatoes at $23 \mathrm{C}$. Survivability was least favorable on carrots and sugar beets; however, M. bovis could still be recovered from both vegetables at 112 days at $-20 \mathrm{C}$ and 14 and 84 days, respectively, for carrots and sugar beets at $8 \mathrm{C}$.

The prolonged survivability of $M$. bovis on feedstuffs commonly used for supplemental feeding of deer would increase the likelihood of transmission of $M$. bovis in areas where $M$. bovis is endemic in whitetailed deer, such as northeastern Michigan. In the current study, survivability of M. bovis was facilitated by decreased temperature, with recovery of viable $M$. bovis from all feedstuffs maintained at $-20 \mathrm{C}$ for 112 days, and recovery of $M$. bovis from apples, corn, hay, and potatoes after maintenance at $8 \mathrm{C}$ for 112 days.

According to historical climate data (http://www.crh.noaa.gov), the average temperature in northeastern Michigan during the period 1971-2000, was $1.4 \mathrm{C}$, $-4.0 \mathrm{C},-7.8 \mathrm{C}$, and $-7.2 \mathrm{C}$ for November, December, January and February, respectively. On average, temperatures during the winter in this region do not exceed $0 \mathrm{C}$ for 55 out of 84 days. Environmental temperatures such as those recorded in winter in northeastern Michigan would increase the likelihood of $M$. bovis survival in the environment.

Supplemental feeding of deer in Michigan consists of placing large piles of feedstuffs, including those examined in the present study, and allowing wildlife free access over the entire winter (Schmitt et al., 1997). The volume of feed at some feeding sites can approach hundreds of thousands of kilograms per winter season (Miller et al., 2003). The results of the present study suggest that $M$. bovis can remain viable on some feedstuff piles for most of the winter with possible exposure of large numbers of deer to viable $M$. bovis. Indeed, analysis has shown that supplemental feeding of deer is associated with the risk of tuberculosis in white-tailed deer (Miller et al., 2003). Specific risk factors include the presence of hardwood forests, other feeding sites in the area, the number of deer fed per year, and the quantity of fruits or vegetables provided (Miller et al., 2003). Interestingly, a commonly observed habit of white-tailed deer may also contribute to disease transmission. During winter, the outer surface of feed piles becomes frozen and deer break small holes, large enough to accommodate the muzzle, through the frozen surface to access nonfrozen feed (Miller et al., 2003). Later, other deer use the same holes to access feed. This habit may concentrate feed contamination to critical areas shared by numerous deer.

Previous studies have examined the ability of $M$. bovis to survive under various environmental conditions (Williams and Hoy, 1930; Maddock, 1933; Duffield and Young, 1985; Jackson et al., 1995; Tanner and Michel, 1999). Although results have varied, ranging from 4 days on pasture (Griffin et al., 2005) to 6 mo in dung (Maddock, 1933), reports have consistently demonstrated that survivability is enhanced in cool, moist conditions, especially when samples are protected from direct sunlight. Moreover, previous studies have taken place under environments commonly encountered in locales such as South Africa (Tanner and Michel, 1999), Australia (Duffield and Young, 1985), New Zealand (Jackson et al., 1995), and the United Kingdom (Williams and Hoy, 1930; Maddock, 1933) and have not considered environments that approach the cold climates of northern Michigan.

Mycobacterium bovis, like other mycobacteria has a unique cell wall, of which lipids account for approximately $60 \%$. This extremely lipophilic cell wall allows $M$. bovis to resist adverse environmental 


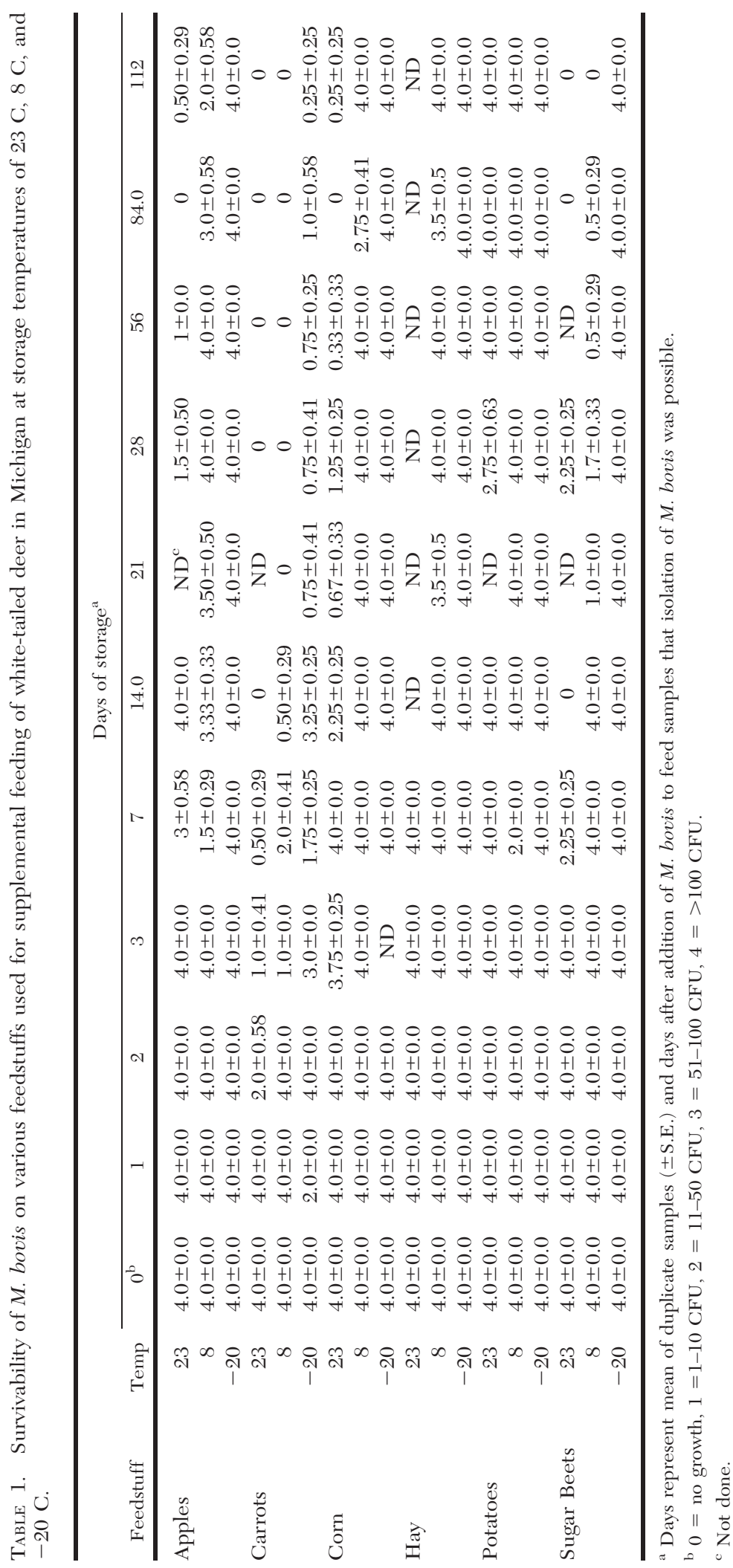


conditions such as drying (Willet, 1992). Cultures maintained at $37 \mathrm{C}$ have been found viable after $12 \mathrm{yr}$ of storage (Willet, 1992). The environment in which the bacilli are found is also critical to prolonged survival in the environment. Bacilli in sputum require $20 \mathrm{hr}$ to $30 \mathrm{hr}$ of exposure to direct sunlight to be killed, whereas bacilli from culture can be killed in $2 \mathrm{hr}$ (Willet, 1992). Previous studies have demonstrated that $M$. bovis-infected white-tailed deer shed the organisms in nasal secretions and saliva (Palmer et al., $2004 \mathrm{a}$, b). It is likely the environment found within these bodily fluids enhances survivability.

Current regulations in Michigan ban supplemental feeding of deer within the TB endemic area (http://www.michigandnr. $\mathrm{com} /$ ) and restrict supplemental feeding in areas where TB has not been identified in deer. However, not all supplemental feeding of wildlife is intentional. Current agricultural practices, such as feeding cattle using hay in large round bales on pastures, do not preclude deer from sharing feed with other deer or livestock in regions where deer have access to livestock pastures.

Limitations of the current study include the lack of ability to evaluate the effect of factors such as moisture (humidity and precipitation); changes in temperature; freeze-thaw cycles; activity of other bacteria, protozoa, or fungi; and ultraviolet light on the survivability of $M$. bovis. It is likely that factors such as these would have a detrimental effect on $M$. bovis survivability. Although not conducted in regions with environmental conditions similar to northern Michigan, other studies conducted in natural settings where factors such as humidity, precipitation, and ultraviolet light were monitored have demonstrated prolonged survivability of $M$. bovis well within the span of time necessary to transmit $M$. bovis indirectly among deer through sharing of feed (Jackson et al., 1995; Tanner and Michel, 1999).

The lack of precise quantitative culture results in the previous study also precludes conclusions concerning the likelihood of the presence of sufficient numbers of organisms at various time-points and their ability to infect white-tailed deer successfully. The dose of $M$. bovis that deer receive during natural infections is unknown and likely highly variable; however, previous experimental studies have demonstrated that low doses of $M$. bovis can produce tuberculous lesions in whitetailed deer (Palmer et al., 2002). Inoculation of 32 white-tailed deer with 300 CFU of the strain of $M$. bovis used in present study resulted in bacterial colonization and lesion formation in all deer (Palmer et al., 2002). Moreover, lesions have been successfully produced in white-tailed deer inoculated with as few as $40 \mathrm{CFU}$ of $M$. bovis (M. Palmer, unpubl. obs.), in red deer with as few as $200 \mathrm{CFU}$ of $M$. bovis (Griffin et al., 2006) and in cattle with a single CFU of $M$. bovis (Dean et al., 2005). This study suggests that contamination of feedstuffs by $M$. bovis infected deer could act as a source of indirect transmission to other deer because $M$. bovis is able to survive in temperatures similar to those recorded during the winter months in northeastern Michigan. Current efforts to ban or control supplemental feeding of deer should have a positive effect on decreasing transmission of $M$. bovis between deer.

\section{LITERATURE CITED}

Dean, G. S., S. G. Rhodes, M. Coad, A. O. Whelan, P. J. Cockle, D. J. Clifford, R. G. Hewinson, AND H. M. Vordermeir. 2005. Minimum infective dose of Mycobacterium bovis in cattle. Infection and Immunity 73: 6467-6471.

Duffield, B. J., AND D. A. Young. 1985. Survival of Mycobacterium bovis in defined environmental conditions. Veterinary Microbiology 10: 193-197.

Frye, G. H. 1995. Bovine tuberculosis eradication: The program in the United States. In Mycobacterium bovis infection in animals and humans, C. O. Thoen and J. H. Steele (eds.). Iowa State University Press, Ames, Iowa, pp. 119-129.

Griffin, J. F. T., C. G. MacKintosh, and C. R. Rodgers. 2006. Factors influencing the protective efficacy of a BCG homologous prime- 
boost vaccination regime against tuberculosis. Vaccine 24: 835-845.

Jackson, R., G. W. Delisle, and R. S. Morris. 1995. A study of the environmental survival of Mycobacterium bovis on a farm in New Zealand. New Zealand Veterinary Journal 43: 346-352.

Maddock, E. C. G. 1933. Studies on the survival time of the bovine tubercle bacillus in soil and dung, in dung and on grass, with experiments on the preliminary treatment of infected organic matter and the cultivation of the organism. Journal of Hygiene 33: 103-117.

Miller, R., J. B. Kaneene, S. D. Fitzgerald, and S. M. Sснмiтt. 2003. Evaluation of the influence of supplemental feeding of white-tailed deer (Odocoileus virginianus) on the prevalence of bovine tuberculosis in the Michigan wild deer population. Journal of Wildlife Diseases 39: 84-95.

O’Brien, D. J., S. D. Fitzgerald, T. J. Lyon, K. L. Butler, J. S. Fierke, K. R. Clarke, S. M. Schmitt, T. M. Cooley, and D. E. Berry. 2001. Tuberculous lesions in free-ranging white-tailed deer in Michigan. Journal of Wildlife Diseases 37: 608-613.

-, S. M. Schmitt, J. S. Fierke, S. A. Hogle, S. R. Winterstein, T. M. Cooley, W. E. Moritz, K. L. Diegel, S. D. Fitzgerald, D. E. Berry, AND J. B. KaneEne. 2002. Epidemiology of Mycobacterium bovis in free-ranging whitetailed deer, Michigan, USA, 1995-2000. Preventive Veterinary Medicine 54: 47-63.

Palmer, M. V., W. R. Waters, and D. L. Whipple. 2002. Lesion development in white-tailed deer (Odocoileus virginianus) experimentally infected with Mycobacterium bovis. Veterinary Pathology 39: 334-340. the transmission of Mycobacterium bovis from deer to cattle through indirect contact. American Journal of Veterinary Research 11: 1483-1489.

- AND - 2004b. Shared feed as a means of deer to deer transmission of Mycobacterium bovis. Journal of Wildlife Diseases 40: 87-91.

Schmitt, S. M., S. D. Fitzgerald, T. M. Cooley, C. S. Bruning-Fann, L. Sullivan, D. Berry, T. Carlson, R. B. Minnis, J. B. Payeur, and J. SIKARSKIE. 1997. Bovine tuberculosis in freeranging white-tailed deer from Michigan. Journal of Wildlife Diseases 33: 749-758.

Tanner, M., AND A. L. Michel. 1999. Investigation of the viability of $M$. bovis under different environmental conditions in the Kruger National Park. Onderstepoort Journal of Veterinary Research 66: 185-190.

Whipple, D. L., R. M. Meyer, D. F. Berry, J. L. Jarnigan, And J. B. Payeur. 1997. Molecular epidemiology of tuberculosis in wild white-tailed deer in Michigan and elephants. In Report of the committee on tuberculosis. Proceedings of the United States Animal Health Association. Pat Campbell and Associates and Spectrum Press, Richmond, Virginia, pp. 543-546.

Willet, H. P. 1992. Mycobacteria, In Zinsser Microbiology, W. K. Joklik, H. P. Willett, D. B. Amos and C. M. Wilfert (eds.). Appleton and Lange, Norwalk, Connecticut, pp. 497-525.

Williams, R. S., and W. A. Hoy. 1930. The viability of B. tuberculosis (bovinus) on pature land, in stored faeces and in liquid manure. Journal of Hygiene 30: 413-419.

Received for publication 25 January 2006. 